\section{Turkish adaptation of Consumers' Perceived Value of Sport Games Scale}

Spor Karşılaşmalarında

Tüketici Değer Algısı Ölçeği'nin Türkçe'ye uyarlama çalışması

\author{
Mehtap Akılli ${ }^{1}$ \\ İsmail Aktaş²
}

Özet

Spor kulüplerinin, birbirleri ile rekabetlerinin yan1 sıra, varlıklarını sürdürebilmeleri için gerekli işletme gelirine sahip olmaları ve bu bağlamda yeterli taraftar kitlesine ulaşmaları gerekmektedir. Tüketici olarak nitelendirilen bu bireylerin değer algılarının ise takımlarına karşı bağl1lıklarında en önemli etmenlerden biri olduğu bilinmektedir. Bu bağlamda spor pazarlamacılarının ve yöneticilerin güçlü bir taraftar kitlesine ulaşabilmeleri için tüketicilerin değer algılarını etkin bir parametre olarak değerlendirmeleri gerekmektedir. Dolayısıyla bu çalışmada, çok boyutlu yapısı ile tüketicilerin değer algilarını değerlendirmeye olanak sağlayan Spor Karşılaşmalarında Tüketici Değer Alg1sı Ölçeği'nin Türkçe literatüre kazandırılması amaçlanmıştır. Araştırmanın analizleri 2018-2019 sezonu Türkiye Spor Toto Süper Lig'de yer alan 18 takım taraftarından alınan iki veri seti aracıllğıyla gerçekleştirilmiştir. Açımlayıcı faktör analizi (AFA) için 254, doğrulayıcı faktör analizi (DFA) için 202 katılımcıdan veri alınmıştır. Beş farklı boyuta yük veren maddelerin faktör yüklerinin 46 ile .87 aralığında olduğunu gösteren AFA sonuçları ve RMSEA değerinin

1 Arş. Gör. Dr., Atatürk Üniversitesi, Spor Bilimleri Fakültesi, mehtapsaatoglu@hotmail.com (iD) Orcid ID: 0000-0002-8444-6864

2 Arş. Gör., Gazi Üniversitesi, Spor Bilimleri Fakültesi, ismailaktas0025@gmail.com (DD Orcid ID: 0000-0002-5471-5787 

of Human Sciences, 17(4), 1123-1136. doi:10.14687/jhs.v17i4.6079

and the other goodness of fit indices are among the acceptable values, showing that the structure tested in Turkish culture is consistent with the original scale. It was observed that the Cronbach alpha coefficients of the relevant subdimensions ranged from .83 to .89 . As a result, it was understood that the measuring tool whose structure was tested was consistent with the original scale, and in line with the findings, the scale was also valid and reliable in Turkish culture.

Keywords: Sport Team Games, Consumer, Perceived Value, Validity, Reliability.

(Extended English summary is at the end of this document)
.081 olduğunu ve diğer uyum iyiliği indekslerinin de kabul edilebilir değerler arasında olduğunu gösteren DFA sonuçları, Türk kültüründe test edilen yapının orijinal ölçekle tutarlı olduğunu göstermiştir. İlgili boyutlarin Cronbach alfa katsayılarinin da .83 ile .89 aralı̆̆ında olduğu gözlenmiştir. Sonuç olarak, yapısı test edilen ölçme aracının orijinal ölçekle tutarlı olduğu ve bulgular doğrultusunda ölçeğin Türk kültüründe de geçerli ve güvenilir bir yapıya sahip olduğu anlaşılmıstır.

Anahtar Kelimeler: Spor Karşılaşmaları, Tüketici, Değer Alg1sı, Geçerlik, Güvenirlik.

\section{Giriş}

Spor bağlamında, iki takım arasındaki oyun, önemli bir gelir kaynağını temsil etmektedir. Birden fazla faktörün oluşturduğu bu gelir kaynağının en önemli öznelerinden biri de tüketici olarak bilinen taraftarlardır. Oyunlara tüketici katılımı, ürün satışları ve sponsorluk anlaşmalarından elde edilen gelirleri de etkileyerek bu gelir kaynağının önemli bir bileşenini oluşturmakta dolayısıyla genel organizasyonel performansta tüketicilerin oynadı̆̆1 rolü de açıklamaktadır (Mason, 1999). Bir spor kulübünün büyümesindeki en önemli gücün taraftar olduğu göz önüne alındığında (The Future of Sports, 2015), kulüplerin gerekli işletme gelirine sahip olmaları için yeterli taraftar kitlesine ulaşmaları gerekmektedir. Güçlü bir taraftar kitlesine ulaşabilmenin de başarılı performansların yanı sıra kulüplerin pazarlama stratejileri ile doğrudan ilişkili olduğu bilinmektedir (da Silva \& Las Casas, 2017). Yapılan bir araştırmaya göre kulüplerin yıllık kazançlarının yaklaşık \%20'sinin maç günü katılımlardan sağlandığ1 (Deloitte, 2014) göz önüne alındığında pazarlama stratejilerinin en önemli belirleyicilerinden birinin de spor etkinlikleri olduğu anlaşılmaktadır.

Bazı araştırmacılar spor etkinliğini genellikle iki ürün kategorisine ayırmaktadır. Birincisi temel hizmet yani oyunun kendisi, ikincisi ise çevresel hizmetlerdir (Mullin, Hardy, \& Sutton, 2014; Zhang, Lam \& Connaughton, 2003). Oyunun kendisine atfedilen durum, tüketicilerin oyunun temel hizmet kalitesini yansıtan ana özelliklere yönelik beklentileri olarak belirtilirken, çevresel hizmetler ise biletler, stadyum hizmetleri, oyun olanakları, mekan erişilebilirliği gibi diğer durumları ifade etmektedir (Byon, Zhang \& Baker, 2013; Zhang, Pease, Hui, \& Michaud, 1995; Zhang, Smith, Pease \& Lam 1998). Dolayısıyla bu iki hizmet kalitesi perspektifi, bir spor takımının mevcut ve potansiyel tüketicilerine sunabileceği oyunun çekici faktörlerini temsil etmektedir (Byon, Zhang \& Connaughton, 2010). Bu nedenle, kulüp yöneticilerinin ve spor pazarlamacilarının, spor mal ve hizmetlerinin kalitesini iyileştirme çabası içinde, oyun tüketimini etkileyen pazarlama faktörlerini daha iyi anlamaları gerekmektedir (Byon, Zhang \& Baker, 2013).

Günümüzde spor etkinliklerine katılımdaki artış, yöneticileri tüketici odaklı yaklaşıma itmektedir. $\mathrm{Bu}$ bağlamda, tüketicilerin tutum ve davranışları bu yaklaşımın yönetimini şekillendirmektedir. Byon, Zhang ve Baker (2013) tüketicilerin, bir spor ürününün önemli faydaları olduğuna veya onlara sosyal statü sağladığına inandıklarında, pazar ortalamasından daha yüksek bir fiyat ödemeye istekli olabileceklerini belirtmektedir. Ayrıca, spor pazarlamacıları bir spor ürününün algılanan değerini artırabilirse, tüketiciler bunun için daha fazla ödeme yapmaya istekli olabilmekte ve spor organizasyonu daha fazla gelir elde edebilmektedir (Byon, Zhang \& Baker, 2013). Bu bağlamda taraftarların takımlarına yönelik değer algıları bu yaklaşımın en önemli unsurlarından birini temsil 
Akıllı, M., \& Aktaş, İ. (2020). Spor Karşılaşmalarında Tüketici Değer Algısı Ölçeği’nin Türkçe’ye uyarlama çalışması. Journal of Human Sciences, 17(4), 1123-1136. doi:10.14687/jhs.v17i4.6079

etmektedir (Byon, Zhang \& Baker, 2013; Cronin, Brady \& Hult, 2000; Hightower, Brady \& Baker, 2002; Murray \& Howat, 2002).

Değer alg1sı, tüketicinin, neyin alındığ1 ve neyin verildiği algısına dayalı olarak bir ürünün faydasına ilişkin genel değerlendirmesi olarak belirtilmektedir (Zeithaml, 1988). Ayrıca McDougall ve Levesque (2000) değer algısını, tüketicilerin verdikleri şey karşllı̆ında aldıklarıyla ilgili bilişsel değerlendirmeleri olarak tanımlamaktadır. Dolayısıyla değer algısı, hizmet kalitesi ile davranışsal niyetler arasındaki ilişkiye aracı bir değişken olarak tanımlanmıştır (Cronin, Brady \& Hult, 2000). Bu nedenle bazı araştırmacılar pazarlamanın, değer algısı dikkate alınmadan açıklanamayacağını belirtmektedirler (Holbrook, 1994; Parasuraman, 1997). Murray ve Howat (2002) spor ürünleri pazarlaması bağlamında yaptıkları çalışmalarında, hizmet kalitesi, memnuniyet, değer algısı ve tüketim niyetleri arasındaki ilişkileri incelemiş ve hizmet kalitesinin değer alg1sı üzerinde doğrudan bir etkiye sahip olduğunu bulgulamışlardır. Ayrıca McDougall ve Levesque (2000) algılanan hizmet kalitesinin ve değer algısının memnuniyeti etkilediğini ve bunun da gelecekteki niyetleri şekillendirdiğini belirtmişlerdir.

Spor bağlamında yapılan araştırmalar, tüketicilerin spor karşılaşmalarına atfettiği değer algısı ile tutumsal ve davranışsal sonuçlar arasındaki ilişkiyi kanıtlamaktadır (Byon, Zhang \& Baker, 2013; Cronin, Brady \& Hult, 2000; Hightower, Brady \& Baker, 2002). Bu tür araştırmalar sporda tüketici değer algısının önemini vurgulasa da bu durumun çok boyutlu bir değer algisı yapısı ile daha geniş perspektiften incelenmesinin daha spesifik bulgulara işaret edeceği düşünülmektedir. Çünkü tüketiciden tüketiciye değişen kişisel bir durumu ifade eden değer algisının (Holbrook, 1994; Zeithaml, 1988) birden fazla değer boyutu ile incelenmesinin daha genel yorumlara olanak sağlayabileceği düşünülmektedir. Dolayısıyla bu çalışmada, çok boyutlu bir yapıya sahip olan Spor Karşılaşmalarında Tüketici Değer Alg1sı Ölçeği’nin Türk kültüründe psikometrik özelliklerinin test edilerek Türkçe literatüre kazandırılması amaçlanmıştır.

\subsection{Araştırma Grubu}

\section{Yöntem}

Spor Karşılaşmalarında Tüketici Değer Alg1sı Ölçeği Türkçe formunun geçerlik ve güvenirlik testleri için gerekli örneklem sayısı literatür önerileri doğrultusunda belirlenmiştir. Bu kapsamda madde sayısının 5 ila 10 katının ilgili analizler için yeterli düzeyde olabileceği anlaşılmıştır (Brown, 2015; Costello \& Osborne 2005; Kline, 2015). Bu doğrultuda Spor Toto Süper Lig 2018-2019 Sezonu'nda yer alan takımların taraftarlarından 254 kişilik bir grup ile açımlayıcı faktör analizi (AFA), 202 kişilik bir grup ile de doğrulayıcı faktör analizi (DFA) gerçekleştirilmiştir. Veriler çevrimiçi anket formu araclly̆̆ıla toplanmıştır. Ölçeğin tamamlanma süresi yaklaşık on dakikalık bir süreye tekabül etmektedir. Farklı takım taraftarlarından oluşan grupların demografik özelliklerine ilişkin bilgiler Tablo 1'de sunulmuştur.

Tablo 1: Çalışma Grubu

\begin{tabular}{|c|c|c|}
\hline Değişkenler & $\begin{array}{c}\text { AFA (N=254) } \\
\%\end{array}$ & $\begin{array}{c}\text { DFA (N=202) } \\
\%\end{array}$ \\
\hline \multicolumn{3}{|l|}{ Cinsiyet } \\
\hline Erkek & 77.6 & 74.8 \\
\hline Kadın & 22.4 & 25.2 \\
\hline Yaş & $\bar{x}=27.19$ & $\bar{x}=27.86$ \\
\hline \multicolumn{3}{|l|}{ Gelir } \\
\hline Düşük & 23.2 & 19.3 \\
\hline Orta & 58.7 & 68.3 \\
\hline Yüksek & 18.1 & 12.4 \\
\hline \multicolumn{3}{|c|}{ Maça gitme sıklığ1 } \\
\hline Nadiren & 29.9 & 39.1 \\
\hline Ara sira & 26.4 & 35.6 \\
\hline S1klikla & 24.4 & 18.8 \\
\hline
\end{tabular}


Akıllı, M., \& Aktaş, İ. (2020). Spor Karşılaşmalarında Tüketici Değer Alg1sı Ölçeği’nin Türkçe’ye uyarlama çalışması. Journal of Human Sciences, 17(4), 1123-1136. doi:10.14687/ihs.v17i4.6079

\begin{tabular}{lcc}
\hline Her zaman & 19.3 & 6.4 \\
\hline Kombine sahipliği & & 15.3 \\
Evet & 29.9 & 84.7 \\
Hayır & 70.1 & 22.8 \\
\hline Deplasmana gitme durumu & & 77.2 \\
Evet & 36.6 & \\
Hayır & 63.4 & 24.3 \\
\hline Taraftar gurubu üyeliği & & 75.7 \\
Evet & 39.8 & 60.2 \\
\hline
\end{tabular}

Çalışma gruplarına ait tanımlayıcı bilgilerin yer aldığı Tablo 1 verileri incelendiğinde, AFA'nın gerçekleştirildiği 27.19 yaş ortalamasına sahip grubun 197'sinin erkek, 57'sinin ise kadın katılımcıdan oluştuğu görülmektedir. Aynı gruptaki katılımcıların \%29.9'u kombine sahibi olduğunu belirtirken \%36.6's1 deplasmana gittiğini belirtmiştir. Ayrıca farklı sıklıklarla maçlara gittiğini belirten katılımcıların \%39.8’inin taraftar gruplarına üye olduğu anlaşılmıştır. Alınan veriler doğrultusunda DFA gerçekleştirilen grubun ise yaş ortalamasının 27.86 olduğu ve katılımcıların 151'inin erkek olduğu görülmektedir. Bu gruptaki katılımcıların da diğer gruptaki katılımcılar gibi genel olarak orta düzey gelire sahip olduğu anlaşılmaktadır. Farklı sıklıklarla maçlara giden katılımcıların \%15.3'ü kombine sahibi olduğunu ve \%22.8’i de deplasmana gittiklerini beyan etmişlerdir. Aynı zamanda katılımcıların \%24.3’ünün taraftar gruplarına üye olduğu anlaşılmaktadır.

\subsection{Veri Toplama Arac1}

Spor Karşılaşmalarında Tüketici Değer Algısı Ölçeği, Kunkel, Doyle ve Berlin (2017) tarafından geliştirilmiştir. Çalışma Almanya profesyonel futbol ligi Bundesliga'da yer alan takımların taraftarları ile gerçekleștirilmiştir. 5 boyut ve 16 maddeden oluşan ölçek 7’li likert tipinde derecelendirilmiştir (1=Kesinlikle Katılmıorum, 7=Kesinlikle Katılıyorum).

Yazarlar, ölçeğin geliştirme sürecini aşamalı bir yaklaşım benimseyerek yürütmüşlerdir. Öncelikle literatür taraması yaparak tüketici değer algısını ifade eden; fonksiyonel, duygusal, ekonomik, sosyal ve epistemik değer olmak üzere 5 boyut tespit etmişlerdir. İkinci aşamada spor pazarlaması alanında çalışan 5 uzmanla bu boyutlar görüşülmüş ve fikirleri alınmıştır. Uzmanlar, bu boyutların tüketici değer algısını temsil ettiğinde hemfikir olmuşlardır. Sürecin diğer aşamasında bu boyutları temsil eden madde yazımına geçilmiş ve 78 madde yazılmıştır. Madde havuzu tekrar uzman görüşüne sunulmuş ve bu görüssler eşliğinde hatalı, benzer ya da boyutları temsil etmeyen 37 madde havuzdan çıkarılmışur. Kalan 41 madde ile analizler gerçekleştirilmiş ve 16 maddelik ölçeğin nihai formu elde edilmiştir. Maddelerin dağılımı ise Fonksiyonel Değer-6 madde, Duygusal Değer-4 madde, Ekonomik Değer-2 madde, Sosyal Değer-2 madde ve Epistemik Değer-2 madde olarak izlenmiştir (Kunkel, Doyle \& Berlin, 2017). Yazarlar ilgili boyutları literatürün de desteği ile spor karşılaşmalarında tüketici değer algısını temsil edecek şekilde tanımlamışlardır.

Fonksiyonel değer, spor takımlarında algılanan kaliteyi ve beklenen performansı temsil etmektedir (Sweeney \& Soutar, 2001). Fonksiyonel değer bir takıma ait stadyum, stadyum çalışanları ve takımın gösterdiği performansla ilgilidir (Kunkel, Doyle \& Berlin, 2017).

Duygusal değer, tüketicilerin ürün ve hizmetleri tükettiklerinde hissettiklerini ifade etmektedir (Keller, 1993; Sheth, Newmann \& Gross, 1991; Sweeney \& Soutar, 2001). Spor takımları, diğer ürün ve hizmetlere kiyasla tüketici ile güçlü duygusal bağlar kurabilir (Kunkel, Doyle \& Berlin, 2017). Kurulan bu bağda en önemli iki güdünün heyecan ve gerçeklerden kaçış olduğu belirtilmektedir (Funk, Filo, Beaton \& Pritchard, 2009; Trail, Robinson, Dick \& Gillentine, 2003; Wann, 1995). Çünkü bu güdülerin tüketicilerin ihtiyaçlarını karşılamayı hedefleyen eylemleri başlattığı bildirilmektedir (Heckhausen \& Heckhausen, 2006). Dolayısıyla bu eylemlerin sonucu tüketicinin duygusal değerini ifade etmektedir.

Ekonomik değer, kısa ve uzun vadeli maliyetlerin algılanması nedeniyle takımların oyunlarından elde edilen faydayı temsil etmektedir (Sweeney \& Soutar, 2001). Bir ürün veya hizmete 
Akıllı, M., \& Aktaş, İ. (2020). Spor Karşılaşmalarında Tüketici Değer Algısı Ölçeği’nin Türkçe’ye uyarlama çalışması. Journal of Human Sciences, 17(4), 1123-1136. doi:10.14687/jhs.v17i4.6079

atfedilen ekonomik değerin, ürün veya hizmetin kalitesiyle ilişkili olarak fiyattan etkilendiği belirtilmektedir (Dodds, Monroe, \& Grewal, 1991; Zeithaml, 1988).

Sosyal değer, sosyal sermayeden elde edilen faydaları temsil etmektedir (Sweeney \& Soutar, 2001). Bir ürünün sosyal değerinin, tüketicileri, ilgili sosyal gruplara bağlama gücünden kaynaklandığ1 öne sürülmektedir (Sheth, Newmann \& Gross, 1991). Spor etkinliklerinin ise tüketicilere sosyal bağ kurma için olanak sağladığı bilinmektedir. Dolayısıyla oyunlardan elde edilen sosyal sermayenin bu bağın temsilcisi olduğu belirtilmektedir (Kunkel, Doyle \& Berlin, 2017).

Epistemik değer, taraftarın, bir spor takımının oyunundan yenilik sağlama ve bilgi edinme arzusunu temsil etmektedir (Sheth, Newmann \& Gross, 1991). Bir taraftarın bilgisinin, bir takıma karşı tutumunu ifade etmektedir (Gladden \& Funk, 2002). Dolayısıyla bir taraftarın takım ile ilgili bilgisi o takıma karşı tepkilerini de etkileyebilmektedir (Kunkel, Doyle \& Berlin, 2017).

\section{3 Çeviri Aşaması}

Spor Karşılaşmalarında Tüketici Değer Algısı Ölçeği’nin psikometrik özelliklerinin Türk kültüründe denenmesi amacıyla yazarlarla e-posta yolu ile iletişime geçilmiş ve gerekli izin ve görüşler alınmıştır. Ölçeğin geliştirildiği çalışma ve ölçek maddelerinin İngilizce formu yazarlar tarafından gönderilmiştir. Ölçme aracının çeviri süreci, önerilen aşamalar (Beaton, Bombardier, Guillemin \& Ferraz, 2000; Brislin, 1970; Çapık, Gözüm \& Aksayan, 2018) takip edilerek yürütülmüştür. Bu aşamalar Şekil 1' de sunulmuştur.

\section{1. ÇEVİRİ}

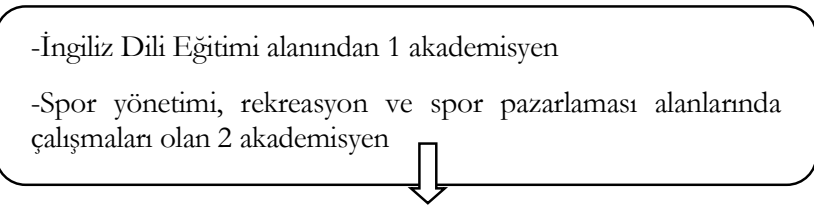

\section{SENTEZ}

Çevirmenlere ek olarak spor yönetimi alanında çalışmaları olan 3 akademisyen ile çeviri versiyonlarının karşılaştırılması ve sentez süreci

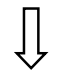

\section{GERİ ÇEVİRİ}

Spor bilimleri alanından olmayan ve ölçeğin orijinal halini bilmeyen anadili İngilizce olan iki uzman tarafindan Türkçe formların tekrar İngilizceye çeviri süreci

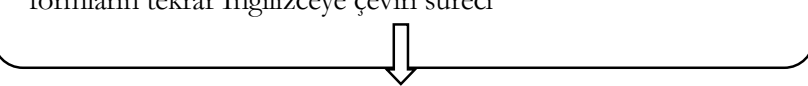

\section{UZMAN DEĞERLENDİRMESİ}

Spor pazarlaması alanında çalışmaları olan 4 kişi ile sürece dahil olan bütün çevirmenlerin ölçeğin bütün versiyonlarını değerlendirip eşdeğerliğine karar verme süreci

\section{5. ÖN TEST}

Ölçeğin son halinin 42 kişilik bir gruba uygulanması ve deneklerin ölçek maddelerini değerlendirme süreci

Şekil 1: Spor Karşılaşmalarında Tüketici Değer Algısı Ölçeği Çeviri Aşamaları

Spor Karşılaşmalarında Tüketici Değer Algisı Ölçeği çeviri sürecinin ilk aşamasında, Spor Bilimleri alanından iki ve İngiliz Dili Eğitimi alanından bir olmak üzere üç akademisyen ölçek maddelerinin Türkçeye çeviri işlemini gerçekleştirmiştir. Çeviri işlemi sonrasında ölçeğin üç 
Akıllı, M., \& Aktaş, İ. (2020). Spor Karşılaşmalarında Tüketici Değer Algısı Ölçeği’nin Türkçe’ye uyarlama çalışması. Journal of Human Sciences, 17(4), 1123-1136. doi:10.14687/jhs.v17i4.6079

formunun sentez sürecine geçilmiştir. Bu aşamada çeviri işlemini gerçekleştiren akademisyenlere ek olarak spor yönetimi alanında çalışmaları olan üç akademisyen sürece dahil olmuş ve ölçeğin üç farklı çevirisinin incelenmesi ve değerlendirilmesi gerçekleştirilmiştir. Üç farklı formda yer alan madde çevirilerinin benzerlikleri ve farklılıkları incelenmiş, eksik ve hatalı yönler irdelenerek güncel bir çeviri formu oluşturulmuştur. Ölçeğin ilk üç çevirisi ve bu çeviri formlarından elde edilen güncel form, Spor Bilimleri alanından olmayan, maddelerin ilk halini bilmeyen ve anadili İngilizce olan iki uzman tarafından tekrar İngilizceye çevrilmiştir. Türkçe ve İngilizce çeviri işlemleri gerçekleştirildikten sonra bu sürece dahil olan tüm çevirmenler ve spor pazarlaması alanında çalışmaları olan 4 kişi olmak üzere toplamda 12 kişiden oluşan bir uzman komitesi oluşturulmuştur. Uzman komitesi bütün çeviri formlarının anlamsal, kavramsal ve dilsel eşdeğerliklerini inceleyerek ölçeğin pilot çalışma öncesi son haline karar vermiştir. Komitenin karar verdiği ölçek formunun son hali ön değerlendirme için Spor Toto Süper Lig 2018-2019 Sezonu'nda yer alan takımların taraftarlarından rastgele belirlenen 42 kişilik bir gruba uygulanmıştır. Katılımcıların maddelerden ne anladıklarına yönelik yürütülen pilot çalışma sonucunda, deneklerden elde edilen dönütler aracllığ ile ölçek formunun nihai hali oluşturulmuştur.

\subsection{Verilerin Analizi}

Spor Karşılaşmalarında Tüketici Değer Algısı Ölçeği’nin Türk kültüründe yapı geçerliğini test etmek amacıyla oluşturulan form ile elde edilen veri seti uygun istatistik programları ile ele alınmıştır. Veri setinde eksik, hatalı ya da uç veriler, veri inceleme ve temizleme yöntemleri ile değerlendirmeye alınmıştır (Rubin, 1976). Eksik kodlanmış veriye rastlanmazken veri girişi esnasında hatalı olduğu belirlenen veriler düzeltilmiştir.

Ölçeğin yapı geçerliğini test etmek amacıyla AFA gerçekleştirilmiştir. Verilerin faktör analizi için uygunluğunu değerlendirmek amaciyla Kaiser-Meyer Olkin (KMO) ve Bartlett Sphericity test bulguları incelenmiştir. Daha sonra faktör varyanslarının daha iyi yorumlanabilmesi için varimax döndürme tekniği kullanılarak AFA uygulanmıştır. Bu analiz sonucunda ölçek yapısının faktör sayısı ve hangi maddelerin hangi faktöre yük verdiği belirlenmiştir.

AFA sonucu ulaşılan yapının uygulamadaki geçerliği DFA gerçekleştirilerek test edilmiştir. Ölçeğin güvenirliği Cronbach alfa katsayısı incelenerek değerlendirilmiştir. Ayrıca maddelerin madde toplam test korelasyonları incelenmiştir. Boyutların birbirleri ile ilişkisi ise korelasyon analizi gerçekleştirilerek değerlendirmeye alınmıştır. İlgili analizler için SPSS 23.0 ve LISREL 8.7 paket programları tercih edilmiştir.

\section{Bulgular}

Spor Karşılaşmalarında Tüketici Değer Algısı Ölçeği’nin yap1 geçerliğini araştırmak amacıyla öncelikle veri setinin uygunluğu test edilmiştir. Bu test sonucunda KMO katsayısı incelenmiş ve .874’lük bir değer aldığı görülmüştür. Verilerin çok değişkenli normal dağılımdan geldiğine işaret eden (Çokluk, Şekercioğlu \& Büyüköztürk, 2014) Bartlett Sphericity testi sonucunun ise ( $x^{2} 3007.096$, $\mathrm{df}=120 \mathrm{p}<.001)$ literatürün belirlediği kriter değerler doğrultusunda kabul edilebilir olduğu anlaşılmıştır (Tabachnick \& Fidel, 2013). Bu sonuçlar doğrultusunda veri setinin geçerlik testleri için uygun olduğuna karar verilmiş ve analizler gerçekleştirilmiştir.

\subsection{Geçerliğe İlişkin Bulgular}

\subsubsection{Açımlayıcı Faktör Analizi}

Orijinal hali 16 maddeden oluşan Spor Karşılaşmalarında Tüketici Değer Alg1sı Ölçeği, AFA ile çözümlenmeye çalışılmıs ve bu maddelerin özdeğeri 1 'in üstünde 5 alt boyutta toplandığ1 görülmüştür. Maddelerin faktör yükleri incelendiğinde hepsinin .40'1n üzerinde olduğu anlaşılmıştır. Birden fazla faktöre yük veren maddeye, muğlak maddeye veya herhangi bir faktöre yük vermeyen maddeye rastlanmamıştır. Maddelerin faktör yükleri incelenerek hangi maddenin hangi faktöre yük verdiği belirlenmiş ve ilk faktöre 6 , ikinci faktöre 4 ve diğer üç faktöre ikişer maddenin yük verdiği anlaşılmıştır. Ölçeğin orijinal halindeki beş boyutlu yapı Türk kültüründe de tutarlık göstermiş ve aynı faktörlere aynı maddelerin yük verdiği anlaşılmıştır. Beş faktörlü olduğu belirlenen yapının alt boyutlarının toplam varyansı açıklama oranları sırasıyla $\% 46.51, \% 10.13, \% 6.65, \% 6.61$ ve $\% 5.46$ olarak izlenmiştir. Bu beş alt boyutun birlikte ölçeğin toplam varyansının yaklaşık \% 75.38 'lik kısmını 
Akıllı, M., \& Aktaş, İ. (2020). Spor Karşılaşmalarında Tüketici Değer Algısı Ölçeği’nin Türkçe’ye uyarlama çalışması. Journal of Human Sciences, 17(4), 1123-1136. doi:10.14687/ihs.v17i4.6079

açıkladığı belirlenmiştir. Spor Karşılaşmalarında Tüketici Değer Algısı Ölçeği’nin beş faktörlü yapısına ilişkin maddelerin dağglımı ve her bir faktöre ait madde istatistikleri Tablo 2'de sunulmuştur.

Tablo 2: Faktör Yükleri, Madde-Toplam Test Korelasyonu ve t Değerleri Sonuçları

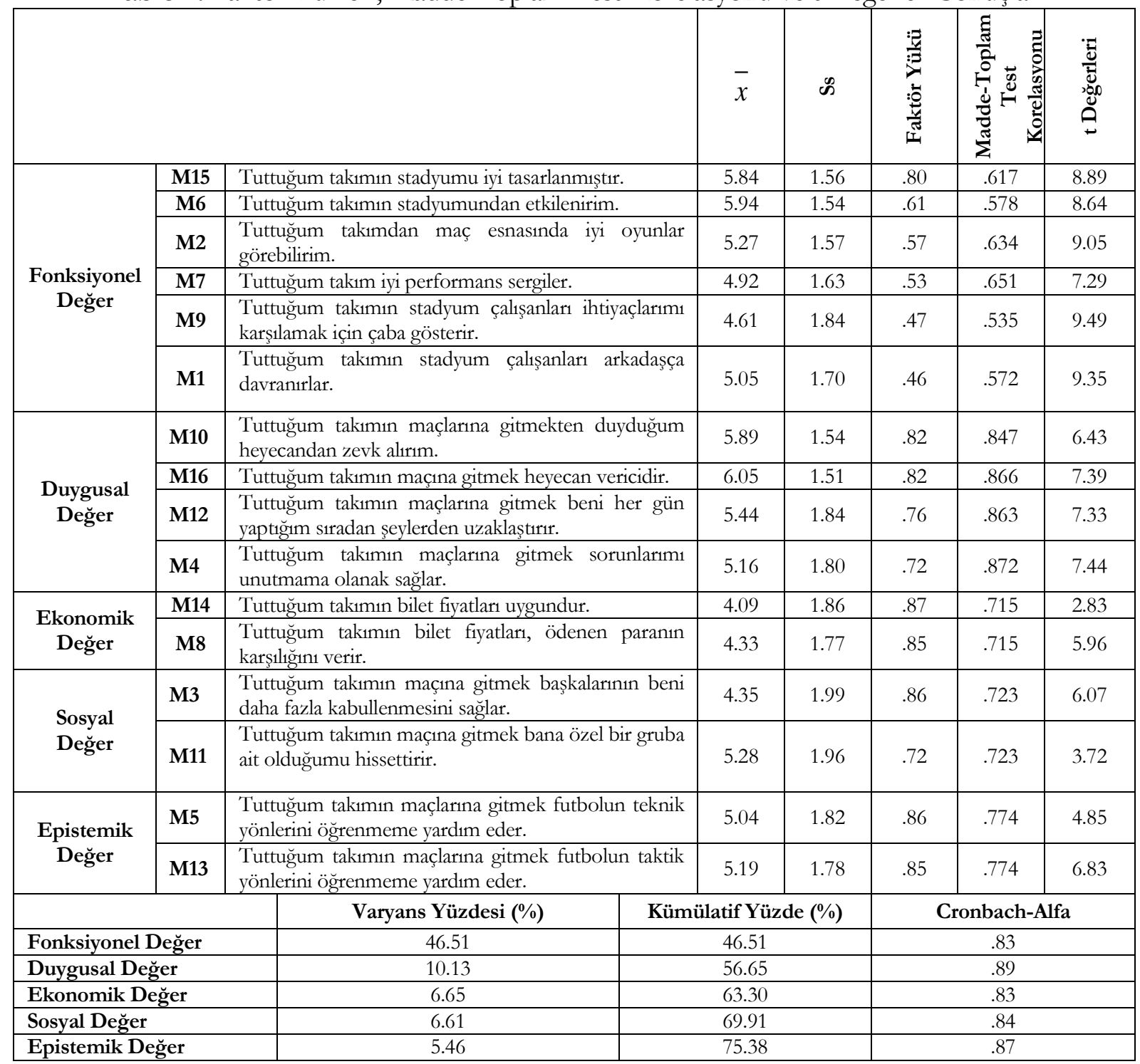

Maddelerin faktör yükleri incelendiğinde birinci alt boyuta yük veren maddelerin .46 ile .80 aralığında, ikinci alt boyuta yük veren maddelerin .72 ile .82 diğer üç alt boyuta yük veren maddelerin ise .72 ile .87 aralığında değer aldıkları görülmüştür. Maddelerin faktör yükleri değişim gösterse de alt boyutlar ölçeğin orijinal hali ile tutarlık göstermiş ve aynı alt boyut isimleri kullanılmıştır. Bu netice ile 6 maddenin oluşturduğu birinci alt boyut "Fonksiyonel Değer" 4 maddeden oluşan ikinci alt boyut "Duygusal Değer" ikişer maddeden oluşan diğer alt boyutlar ise sirasiyla "Ekonomik Değer", "Sosyal Deger" ve "Epistemik Değer" olarak isimlendirilmiştir. Alt boyutların özdeğerlerinin, maddelerin faktör yüklerinin ve 5 alt boyutlu yapının toplam varyansı açıklama yüzdesinin literatürde önerilen kesme değerlerin (Çokluk, Şekercioğlu \& Büyüköztürk, 2014; Nunnally \& Bernstein, 1994; Tabachnick \& Fidel, 2013; Thompson, 2004) üzerinde olduğu anlaşılmış ve bu bulgular eşliğinde, madde istatistikleri yeterli düzeyde yapı geçerliğinin kanıtı olarak sunulmuştur. 

of Human Sciences, 17(4), 1123-1136. doi:10.14687/jhs.v17i4.6079

Tablo 3: Korelasyon Analizi Sonuçları

\begin{tabular}{|c|c|c|c|c|c|c|}
\hline Değişkenler & $\begin{array}{c}\text { Fonksiyonel } \\
\text { Değer }\end{array}$ & $\begin{array}{c}\text { Duygusal } \\
\text { Değer }\end{array}$ & $\begin{array}{c}\text { Ekonomik } \\
\text { Değer }\end{array}$ & Sosyal Değer & $\bar{x}$ & SS \\
\hline $\begin{array}{c}\text { Fonksiyonel } \\
\text { Değer }\end{array}$ & - & & & & 5.27 & 1.20 \\
\hline $\begin{array}{l}\text { Duygusal } \\
\text { Değer }\end{array}$ & $.645^{*}$ & - & & & 5.64 & 1.46 \\
\hline $\begin{array}{l}\text { Ekonomik } \\
\text { Değer }\end{array}$ & $.513^{*}$ & $.403^{*}$ & - & & 4.21 & 1.68 \\
\hline $\begin{array}{l}\text { Sosyal } \\
\text { Değer }\end{array}$ & $.604 *$ & $.594 *$ & $.394 *$ & - & 4.82 & 1.83 \\
\hline $\begin{array}{l}\text { Epistemik } \\
\text { Değer }\end{array}$ & $.547 *$ & $.524 *$ & $.352^{*}$ & $.492^{*}$ & 5.11 & 1.70 \\
\hline
\end{tabular}

Ölçeğin alt boyutlanının ilişki katsayıları incelendiğinde faktörlerin birbirleri ile orta düzeyde bir ilişkisi olduğu anlaşılmıştır. Korelasyon analizi sonucu en yüksek ilişkinin "Fonksiyonel Değer" ile "Duygusal Değer" alt boyutları arasında olduğu anlaşılmıştur ( $\mathrm{r}=.65)$.

\subsubsection{Doğrulayıcı Faktör Analizi}

AFA sonucunda Orijinal ölçekle tutarlık gösteren 5 alt boyutlu yapı DFA gerçekleştirilerek uygulamadaki geçerliği test edilmeye çalışılmıs ve LISREL 8.7 paket programı aracilığıla ulaşılan yapı standardize edilmiş hata varyansları ile Şekil 2'de sunulmuştur.

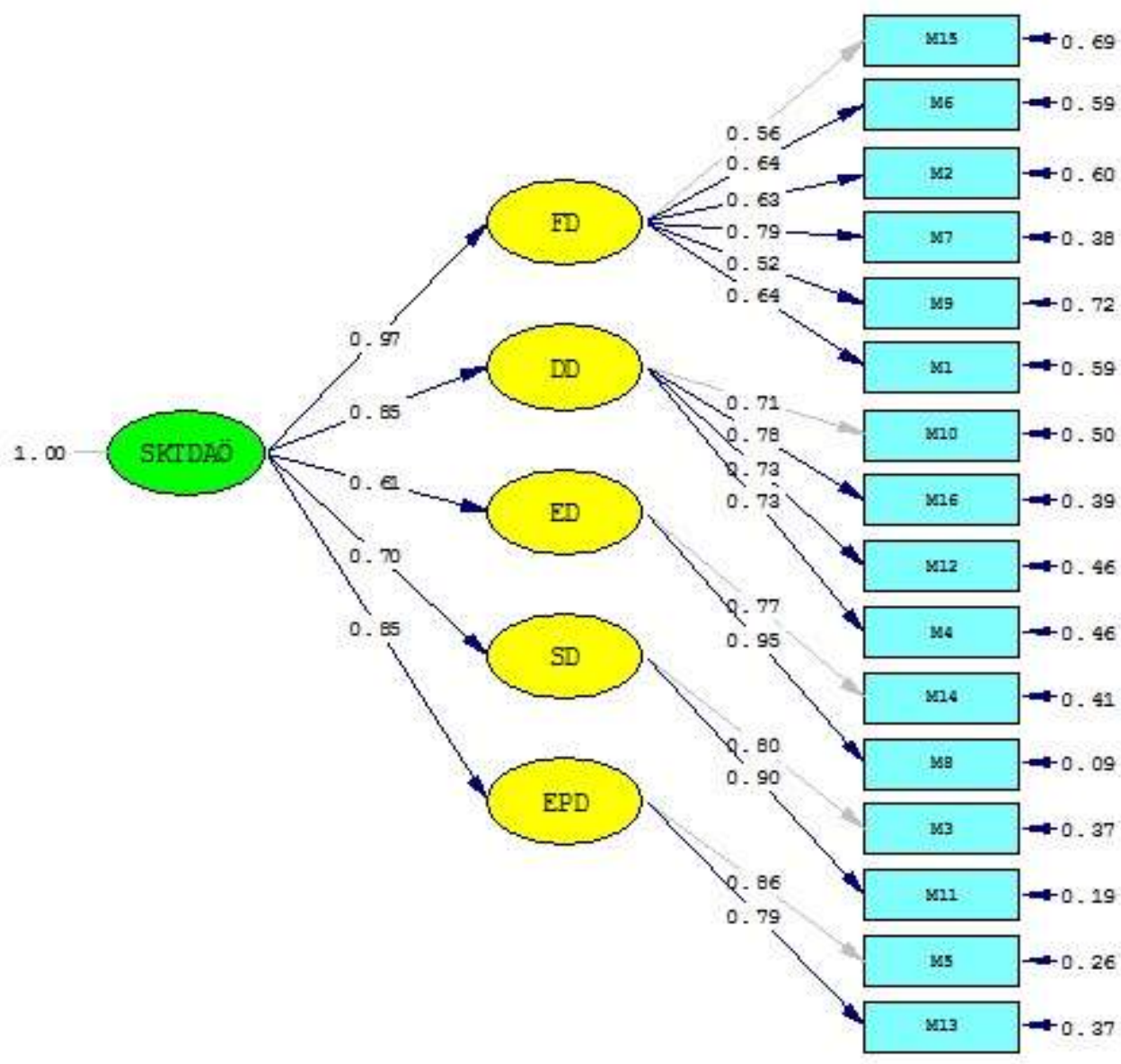

Chi-3quare $=207.80, d f=90, p-v a l u e=0.00000$, RySEA $=0.081$

Şekil 2: Yol Şeması 
Akıllı, M., \& Aktaş, I. (2020). Spor Karşılaşmalarında Tüketici Değer Algısı Ölçeği'nin Türkçe'ye uyarlama çalışması. Journal of Human Sciences, 17(4), 1123-1136. doi:10.14687/jhs.v17i4.6079

Spor Karşılaşmalarında Tüketici Değer Algisı Ölçeği’nin 5 alt boyut ve 16 maddeden oluşan yapısının DFA sonucu ulaşılan uyum iyiliği indeksleri Tablo 4' de sunulmuştur.

Tablo 4: Doğrulayıcı Faktör Analizi Sonuçları

\begin{tabular}{lllllllllllll}
\hline$\chi^{2}$ & $\mathbf{d f}$ & $\mathbf{p}$ & $\begin{array}{l}\chi^{2} / \\
\mathbf{d f}\end{array}$ & \multirow{2}{*}{ RMSEA } & RMR & SRMR & GFI & AGFI & NFI & NNFI & CFI & IFI \\
\hline 207.80 & 90 & .00 & 2.31 & .081 & .19 & .07 & .89 & .83 & .95 & .96 & .97 & .97 \\
\hline
\end{tabular}

Ölçeğin DFA sonucu ulaşılan yapısına ilişkin bulgular incelendiğinde, modelin RMSEA değerinin .081 olduğu görülmüştür. Literatürde bu değerin .08 ve altında olmasının kabul edilebilir bir değer olduğu belirtilmektedir (Brown, 2015; Harrington, 2009; Kline, 2015). Bu kriter değer eşliğinde, RMSEA değerinin modele ilişkin kabul edilebilir uyuma işaret ettiği anlaşılmaktadır. Ayrıca ulaşılan yapının diğer uyum iyiliği indeksleri de incelenmiş ve modele ilişkin uyumun varllğı yorumlanmaya çalışılmıştır. Literatür incelendiğinde $\chi^{2} / \mathrm{df}$ değerinin 3'ün altında olmasının mükemmel uyuma, 5 'in altında olmasının kabul edilebilir bir uyuma işaret ettiği anlaşılmıştır (Kline, 2015; Tabachnick \& Fidell, 2013). Bu bilgi doğrultusunda modelin 2.31'lik $\chi^{2} /$ df değerinin mükemmel uyum olduğuna kanaat getirilmiştir. Diğer uyum iyiliği indekslerinin de $(\mathrm{RMR}=.19, \mathrm{SRMR}=.07, \mathrm{GFI}=.89, \mathrm{AGFI}=.83$, $\mathrm{NFI}=.95$, NNFI=.96, CFI=.97, IFI=.97) kesme değerler (Brown, 2015; Harrington, 2009; Hu \& Bentler, 1999; Kline, 2015; Tabachnick \& Fidell, 2013) doğrultusunda kabul edilebilir olduğu görülmüştür. Literatürün desteklediği bu sonuçlar eşliğinde Spor Karşılaşmalarında Tüketici Değer Algısı Ölçeği'nin AFA sonucu elde edilen yapısının DFA ile uygulamada da doğrulandığı anlaşılmış ve bu bulgular kanit olarak sunulmuştur.

\subsection{Güvenirliğe İlişin Bulgular}

Spor Karşılaşmalarında Tüketici Değer Alg1sı Ölçeği’nin güvenirliğine ilişkin değerlendirme, Cronbach alfa katsayıları referans alınarak yorumlanmıştır. Ayrıca her bir maddenin, ölçülmek istenen özelliği ölçüp ölçmediğine dair madde geçerliğine kanıt sağlamak için madde-toplam test korelasyonlarını incelenmiştir. Bu analizler sonucu, "Fonksiyonel Değer" alt boyutunun güvenirlik katsayıs1 .83, "Duygusal Değer" alt boyutunun güvenirlik katsayıs1 .89, "Ekonomik Değer" alt boyutunun güvenirlik katsayıs1 .83, "Sosyal Değer" alt boyutunun güvenirlik katsayıs1 .84 ve "Epistemik Değer" alt boyutunun güvenirlik katsayısı ise .87 olarak hesaplanmıştır (Tablo 2). Ölçeğin tamamına ilişkin güvenirlik katsayısı ise .91 olarak belirlenmiştir. Tablo 2'de belirtilen madde toplam test korelasyonları incelendiğinde, "Fonksiyonel Degere" alt boyutunda yer alan maddelerin .54 ile .65, "Duygusal Değer" alt boyutunda yer alan maddelerin .85 ile .87, "Ekonomik Değer", "Sosyal Değer" ve "Epistemik Değer" alt boyutlarında yer alan maddelerin ise .72 ile .77 aralığında değer aldıkları görülmektedir. Literatürün belirlediği kriter değerlerin (Nunnally \& Bernstein 1994) üzerinde olan bu değerler ölçme aracının güvenilir olduğuna işaret etmektedir.

AFA, DFA ve güvenirlik analizleri sonucu ulaşılan bulguların, Spor Karşılaşmalarında Tüketici Değer Algısı Ölçeği'nin orijinal ölçekle tutarlı bir yapıya işaret ettiği anlaşılmış ve Türk kültüründe de ölçeğin geçerli ve güvenilir bir yapı sağladığına kanaat getirilmiştir.

\section{Tartışma ve Sonuç}

Bu çalışmada Spor Karşılaşmalarında Tüketici Değer Alg1sı Ölçeği’nin Türk kültüründe psikometrik özellikleri incelenmiş ve mevcut yapı kanıt olarak sunulmuştur. İki farklı̈rneklem grubu ile AFA ve DFA gerçekleștirilerek ölçeğin orijinal yapısı ile tutarlılık gösterdiği anlaşılmıştır. Bu sonuçlarla ölçeğin Türk kültüründe de 16 madde ve 5 boyuttan oluştuğu gözlenmiştir. Maddelerin aynı alt boyutlara yük verdiği izlendiği için alt boyutların isimlendirilmesi orijinal ölçek baz alınarak gerçekleştirilmiştir. Bu doğrultuda alt boyutlar "Fonksiyonel Değer", "Duygusal Değer", "Ekonomik Değer", "Sosyal Değer" ve "Epistemik Değer" olarak isimlendirilmiştir. Yapilan analizler sonucu ölçeğin Türk kültüründe de geçerli ve güvenilir bir yapıya sahip olduğuna kanaat getirilmiştir. 
Akıllı, M., \& Aktaş, İ. (2020). Spor Karşılaşmalarında Tüketici Değer Algısı Ölçeği’nin Türkçe’ye uyarlama çalışması. Journal of Human Sciences, 17(4), 1123-1136. doi:10.14687/jhs.v17i4.6079

Pazarlama için en önemli unsurlardan biri olarak belirtilen değer algısı (Byon, Zhang \& Baker, 2013; Cronin, Brady \& Hult, 2000; Hightower, Brady \& Baker, 2002; Murray \& Howat 2002) literatürde farklı özellikler kapsamında incelenmeye çalışılmıştır (Eskiler \& Altunışı, 2015; Jin, Lee, \& Lee, 2013; Kazançoğlu \& Baybars, 2016; Nuviala, Grao-Cruces, Pérez-Turpin, \& Nuviala, 2012; Şener \& Behdioğlu, 2013). Değer algısı ile ilgili bazı çalışmalar incelendiğinde bu faktörün genellikle tek boyut olarak incelendiği ve çoğunlukla ekonomi ile ilişkilendirildiği görülmüsstür (Byon, Zhang \& Baker, 2013; Cronin, Brady \& Hult, 2000; Hightower, Brady \& Baker, 2002; Howat \& Assaker, 2013; Kwon, Trail \& James, 2007). Ancak bazı araştırmacılar değer algısının birden fazla boyuta sahip olduğunu ve bu boyutlarla birlikte incelenmesinin daha sağllklı sonuçlar verebileceğini vurgulamışlardır (Kunkel, Doyle \& Berlin, 2017; Lee, Trail, Kwon \& Anderson, 2011; Sweeney \& Soutar, 2001). Çünkü değer algısının detaylı olarak incelenmesi neticesinde, pazarlamacı ile tüketici arasındaki ilişkide daha tutarlı sonuçlara ulaşılabileceği vurgulanmaktadır (Kunkel, Doyle \& Berlin, 2017; Lee, Trail, Kwon \& Anderson, 2011). Dolayısiyla spor pazarlamacılarının ve yöneticilerinin değer algısını çok yönlü olarak değerlendirmesinin, tüketici ile aralarındaki bağın sağlamlığını artırabileceği ve bu sayede pazarlama stratejilerindeki istenilen sonuçlara ulaşılabileceği düşünülmektedir. Bu bağlamda uyarlaması gerçekleştirilen ölçme aracının çok boyutlu yapısının, spor karşılaşmaları özelinde tüketicilerin değer alg1larının değerlendirilmesinde faydalı olabileceği düşünülmektedir.

Mevcut araştırma spor karşılaşmaları özelinde, tüketicilerin değer algısını değerlendirmeye uygun, kavramsal olarak sağlam ve pratik olarak yararlı çok boyutlu bir ölçek sunarak literatüre, spor pazarlamacılarına ve bu alanda çalışan araşurmacılara destek sağlamaktadır. Kavramsallaştırılmış ve birbiri ile ilişkili çok boyutlu bu yapı, tüketicilerin taraftarı oldukları takımların karşılaşmalarına yönelik değerlerinin genel bir yansıması olarak değerlendirilmektedir. Bu yapının, tüketicilerin takımlarına yönelik tutumlarının öncülü olabildiği belirtilmektedir (Kunkel, Doyle \& Berlin, 2017). Dolayısıyla literatürdeki tek boyutlu değerlendirmelere nazaran çok boyutlu bu yaklaşımın tüketicinin değer algısının genel değerlendirmesine olanak sağlayabileceği düşünülmektedir.

Spor Karşılaşmalarında Tüketici Değer Algısı Ölçeği'nin 5 boyutlu yapısı tek başına bir değerlendirmeyi ifade edebileceği gibi her bir boyutta kendi içinde bir değerlendirmeye olanak sağlamaktadır. Farklı madde sayılarına sahip boyutlara atfedilen maddelere denekler tarafindan verilen derecelendirme (7’li likert) arttıkça ilgili boyuta yönelik değer algısının da arttığı anlaşılmaktadır. Dolayısıyla deneklerin alabileceği yüksek puanlar değer algılarındaki pozitif yönlü değerlendirmeye olanak sunmaktadır.

Taraftarların takımlarına yönelik değer algılarının çok boyutlu bir değerlendirmesine olanak sağlayan bu ölçme aracı ile tüketicilerin takımlarına yönelik tutum, memnuniyet ve bağlılıklarının da tahminine imkan sağlayacağı düşünülmektedir (Kunkel, Doyle \& Berlin, 2017). Ayrıca ölçek, farklı boyutlarla ele alınan değer algısının, spor pazarlamacılarına strateji belirlerken değerlendirmeye alabilecekleri bir yapıyı ifade etmektedir.

Araştırmanın, Spor Toto Süper Lig 2018-2019 Sezonu'nda yer alan takımların taraftarları kapsamında gerçekleştirilmesi, çalışmanın sınırlılığı olarak söylenebilir. Ölçme aracının farklı ligler kapsamında da değerlendirilmesinin ölçeğin tutarllğını destekleyeceği düşünülmektedir. Ayrıca, sadece futbol branşı kapsamında gerçekleştirilen bu çalışmanın başka branşlarla da değerlendirilerek mevcut yapının incelenmesinin alana katkı sağlayacağı düşünülmektedir.

Sonuç olarak bu çalışmanın bulguları, uyarlaması gerçekleştirilen Spor Karşılaşmalarında Tüketici Değer Alg1sı Ölçeği’nin Türk kültüründe de orijinal yapı ile tutarlı olduğunu göstermiştir. Ölçeğin çok boyutlu yapısının, tüketicilerin taraftarı oldukları takıma yönelik değer algılarını değerlendirme noktasında, öngörü niteliğinde olduğu söylenebilir. Ayrıca birbirinden farklı beş tüketici değeri kapsayan bu ölçek, spor pazarlamacılarına ve spor yöneticilerine teorik olarak sağlam ve uygulanabilirlik açısından güvenilir bir yapı sunmaktadır. 
Akıllı, M., \& Aktaş, İ. (2020). Spor Karşılaşmalarında Tüketici Değer Algısı Ölçeği'nin Türkçe'ye uyarlama çalışması. Journal of Human Sciences, 17(4), 1123-1136. doi:10.14687/ihs.v17i4.6079

\section{Kaynaklar}

Beaton, D. E., Bombardier, C., Guillemin, F., \& Ferraz, M. B. (2000). Guidelines for the process of cross-cultural adaptation of self-report measures. Spine, 25(24), 3186-3191.

Brislin, R. W. (1970). Back-translation for cross-cultural research. Journal of cross-cultural psychology, 1(3), 185-216. doi.org/10.1177/135910457000100301

Brown, T. A. (2015). Confirmatory factor analysis for applied research. (2nd ed.) New York: Guilford Press.

Byon, K. K., Zhang, J. J., \& Baker, T. A. (2013). Impact of core and peripheral service quality on consumption behavior of professional team sport spectators as mediated by perceived value. European Sport Management Quarterly, 13(2), 232-263. doi.org/10.1080/16184742.2013.767278

Byon, K. K., Zhang, J. J., \& Connaughton, D. P. (2010). Dimensions of general market demand associated with professional team sports: Development of a scale. Sport Management Review, 13(2), 142-157. doi.org/10.1016/j.smr.2009.07.005

Çapık, C., Gözüm, S., \& Aksayan, S. (2018). Kültürlerarası ölçek uyarlama aşamaları, dil ve kültür uyarlamas1: Güncellenmiş rehber. Florence Nightingale Hemşirelike Dergisi, 26(3), 199-210. doi.org/10.26650/FNJN397481

Çokluk, Ö., Şekercioğlu, G., \& Büyüköztürk, Ş. (2014). Sosyal bilimler için çok değğskenli istatistik: SPSS ve LISREL uygulamalar. Ankara: Pegem Akademi.

Costello, A. B., \& Osborne, J. (2005). Best practices in exploratory factor analysis: Four recommendations for getting the most from your analysis. Practical assessment, research, and evaluation, 10(7), 1-9.

Cronin, J., Brady, M. K., \& Hult, T. M. (2000). Assessing the effects of quality, value, and customer satisfaction on consumer behavioral intentions in service environments. Journal of Retailing, 76(2), 193-218. doi.org/10.1016/S0022-4359(00)00028-2

da Silva, E. C., \& Las Casas, A. L. (2017). Sport fans as consumers: An approach to sport marketing. British Journal of Marketing Studies, 5(4), 36-48.

Dodds, W. B., Monroe, K. B., \& Grewal, D. (1991). Effects of price, brand, and store information on buyers' product evaluations. Journal of marketing research, 28(3), 307-319. doi.org/10.1177/002224379102800305

Eskiler, E., \& Altunışı, R. (2015). Algılanan değer ve müşteri memnuniyetinin satın alma eğilimleri üzerine etkisi. III. Rekereasyon Arastirmalar Kongresi, 483-493.

Funk, D. C., Filo, K., Beaton, A. A., \& Pritchard, M. (2009). Measuring the motives of sport event attendance: Bridging the academic-practitioner divide to understanding behavior. Sport Marketing Quarterly, 18(3), 126-138.

Gladden, J. M., \& Funk, D. C. (2002). Developing an understanding of brand associations in team sport: Empirical evidence from consumers of professional sport. Journal of Sport management, 16(1), 54-81. doi.org/10.1123/jsm.16.1.54

Harrington, D. (2009). Confirmatory factor analysis. New York: Oxford University Press.

Heckenhausen, J., \& Heckenhausen, H. (2006). Motivation und Handeln (3rd ed.). Heidelberg: Springer.

Hightower, R., Brady, M. K., \& Baker, T. L. (2002). Investigating the role of the physical environment in hedonic service consumption. An exploratory study of sporting events. Journal of Business Research, 55(9), 697-707. doi.org/10.1016/S0148-2963(00)00211-3

Holbrook, M. B. (1994). The nature of consumer value. In R. T. Rust \& R. L. Oliver (Eds.), Service quality: New directions in theory and practice. Newbury Park, CA: Sage.

Howat, G., \& Assaker, G. (2013). The hierarchical effects of perceived quality on perceived value, satisfaction, and loyalty: Empirical results from public, outdoor aquatic centres in Australia. Sport Management Review, 16(3), 268-284. doi.org/10.1016/j.smr.2012.10.001

Hu, L. T., \& Bentler, P. M. (1999). Cutoff criteria for fit indexes in covariance structure analysis: Conventional criteria versus new alternatives. Structural equation modeling: a multidisciplinary journal, 6(1), 1-55. doi.org/10.1080/10705519909540118 
Akıllı, M., \& Aktaş, İ. (2020). Spor Karşılaşmalarında Tüketici Değer Algısı Ölçeği'nin Türkçe'ye uyarlama çalışması. Journal of Human Sciences, 17(4), 1123-1136. doi:10.14687/jhs.v17i4.6079

Jin, N., Lee, S., \& Lee, H. (2015). The effect of experience quality on perceived value, satisfaction, image and behavioral intention of water park patrons: New versus repeat visitors. International Journal of Tourism Research, 17(1), 82-95. doi.org/10.1002/jtr.1968

Jones, D. (Ed.) (2010). Deloitte football money league. Manchester, UK: Deloitte Sports Business Group.

Kazançoğlu, İ., \& Baybars, M. (2016). Lisanslı spor ürünlerinin algilanan değer bileşenlerinin satın alma niyeti ile ilişkisi: Türkiye'nin en büyük üç futbol kulübünün incelenmesi. Doğus Üniversitesi Dergisi, 17(1), 51-66.

Keller, K. L. (1993). Conceptualizing, measuring, managing customer-based brand equity. Journal of Marketing, 57(1), 1-22. doi.org/10.1177/002224299305700101

Kline, R. B. (2015). Principles and practice of structural equation modeling. New York: Guilford Press.

Kunkel, T., Doyle, J. P., \& Berlin, A. (2017). Consumers' perceived value of sport team games-A multidimensional approach. Journal of Sport Management,31(1), 80-95. doi.org/10.1123/jsm.2016-0044

Kwon, H. H., Trail, G., \& James, J. D. (2007). The mediating role of perceived value: Team identification and purchase intention of team-licensed apparel. Journal of Sport Management, 21(4), 540-554. doi.org/10.1123/jsm.21.4.540

Lee, D., Trail, G. T., Kwon, H. H., \& Anderson, D. F. (2011). Consumer values versus perceived product attributes: Relationships among items from the MVS, PRS, and PERVAL scales. Sport Management Review, 14(1), 89-101. doi.org/10.1016/j.smr.2010.05.001

Mason, D. S. (1999). What is the sports product and who buys it? The marketing of professional sports leagues. European Journal of Marketing, 33(3), 402-418. doi.org/10.1108/03090569910253251

McDougall, G. H. G., \& Levesque, T. (2000). Customer satisfaction with services: Putting perceived value into the equation: An empirical examination. Journal of Services Marketing, 14(5), 392_410. doi.org/10.1108/08876040010340937

Mullin, B. J., Hardy, S., Sutton, W. A. (2014). Sport Marketing. (4th ed.) Champaign: Human Kinetics.

Murray, D., \& Howat, G. (2002). The relationships among service quality, value, satisfaction, and future intentions of customers at an Australian sports and leisure centre. Sport Management Review, 5(1), 25-43. doi.org/10.1016/S1441-3523(02)70060-0

Nunnally, J. C., \& Bernstein, I. H. (1994). Psychometric theory (3rd ed.). New York: McGrawHill.

Nuviala, A., Grao-Cruces, A., Pérez-Turpin, J. A., \& Nuviala, R. (2012). Perceived service quality, perceived value and satisfaction in groups of users of sports organizations in Spain. Kinesiology, 44(1), 94-103.

Parasuraman, A. (1997). Reflections on gaining competitive advantage through customer value. Journal of the Academy of marketing Science, 25(2), 154-161.

Rubin, D. B. (1976). Inference and missing data. Biometrika, 63(3), 581-592. doi.org/10.1093/biomet/63.3.581

Şener, H. Y., \& Behdioğlu, S. (2013). Müşteri Sadakati Oluşturmada Müşterinin Algiladı̆̆1Değer, Memnuniyet ve Rakip İşletmeye Geçme Maliyeti: Bir Spor Merkezinde İstatiksel Uygulama. Selçk Üniversitesi Sosyal Bilimler Enstitüsü Dergisi, 30, 165-180.

Sheth, J. N., Newman, B. I., \& Gross, B. L. (1991). Why we buy what we buy: A theory of consumption values. Journal of business research, 22(2), 159-170. doi.org/10.1016/01482963(91)90050-8

Sweeney, J. C., \& Soutar, G. N. (2001): Consumer perceived value. The development of a multiple item scale. Journal of Retailing, 77(2), 203-220. doi.org/10.1016/S0022-4359(01)00041-0

Tabachnick, B. G., \& Fidel, L. S. (2013). Using Multivariate Statistics, (6th ed.) Boston: Pearson.

The Future of Sports (2015). http:/ / www.gannett-cdn.com/usatoday/editorial/sports/The-Futureof-Sports-2015-Report.pdf sayfasından erişilmiştir.

Thompson, B. (2004). Exploratory and confirmatory factor analysis: Understanding concepts and applications. American Psychological Association. 
Akıllı, M., \& Aktaş, İ. (2020). Spor Karşılaşmalarında Tüketici Değer Algısı Ölçeği'nin Türkçe'ye uyarlama çalışması. Journal of Human Sciences, 17(4), 1123-1136. doi:10.14687/jhs.v17i4.6079

Trail, G. T., Robinson, M. J., Dick, R. J., \& Gillentine, A. J. (2003). Motives and points of attachment: Fans versus spectators in intercollegiate athletics. Sport Marketing Quarterly, 12(4), 217-227.

Wann, D. L. (1995). Preliminary validation of the sport fan motivation scale. Journal of Sport and Social issues, 19(4), 377-396. doi.org/10.1177/019372395019004004

Zeithaml, V. A. (1988). Consumer perceptions of price, quality, and value: a means-end model and synthesis of evidence. Journal of marketing, 52(3), 2-22. doi.org/10.1177/002224298805200302

Zhang, J. J., Lam, E. T. C., \& Connaughton, D. P. (2003). General market demand variables associated with professional sport consumption. International Journal of Sports Marketing and Sponsorship, 5(1), 33-55. doi.org/10.1108/IJSMS-05-01-2003-B003

Zhang, J. J., Pease, D. G., Hui, S. C., \& Michaud, T. J. (1995). Variables affecting the spectator decision to attend NBA games. Sport Marketing Quarterly, 4(4), 29-39.

Zhang, J. J., Smith, D. W., Pease, D. G., \& Lam, E.T.C. (1998). Dimensions of spectator satisfaction toward support programs of professional hockey games. International Sports Journal, 2(2), 1-17.

\section{Extended English Summary}

\section{Introduction}

Consumer participation in games constitutes an important component of this source of income by also affecting the revenues from the sales of goods and sponsorship, thus explaining the role of consumers in overall organizational performance (Mason, 1999). Considering that the most important force in the growth of a sports team is its fans (Future of Sport, 2015), teams need to reach a sufficient fanbase with the necessary operating income. It is known that reaching a strong fanbase is directly related to the marketing strategies of teams as well as successful performances (da Silva \& Las Casas, 2017). Some researchers generally divide sports activity into two product categories. The first is product or service, the game itself, and the second is service environment (Mullin, Hardy, \& Sutton, 2014; Zhang, Lam \& Connaughton, 2003). These two service quality perspectives represent the attractive factors of the game that a sports team can offer to its current and potential consumers (Byon, Zhang \& Connaughton, 2010). Therefore, club managers and sports marketers need to better understand the marketing factors that affect game consumption in an effort to improve the quality of sports products and services (Byon, Zhang \& Baker, 2013). Today, the increase in participation in sports events pushes managers to a consumer-oriented approach. In this context, fans' perceived value towards their teams represent one of the most important elements of this approach (Byon, Zhang \& Baker, 2013; Cronin, Brady \& Hult, 2000; Hightower, Brady \& Baker, 2002; Murray \& Howat, 2002). Research in the context of sports proves the relationship between the perceived value attributed by consumers to sports events and attitudinal and behavioral outcomes (Byon, Zhang \& Baker, 2013; Cronin, Brady \& Hult, 2000; Hightower, Brady \& Baker, 2002). It is thought that examining this situation from a broader perspective with a multi-dimensional perceived value structure will indicate more specific findings. Therefore, in this study, it is aimed to test the psychometric properties of the Consumers' Perceived Value of Sport Games Scale, which has a multidimensional structure, in Turkish culture and add it to the Turkish literature.

\section{Method}

In the study, EFA was performed with a group of 254 fans of the teams in the Spor Toto Super League 2018-2019 Season, and CFA was performed with a group of 202 people. Of the group with an average age of 27.19, where EFA was carried out, 197 were male and 57 were female participants. In line with the data obtained, it was determined that the average age of the group in which CFA was performed was 27.86 and 151 of the participants were men. Consumers' Perceived Value of Sport Games Scale was developed by Kunkel, Doyle, and Berlin (2017). The scale consisting of 5 sub-dimensions and 16 items is graded in 7-point Likert type. The translation process of the measurement tool was carried out by following the suggested stages (Beaton, Bombardier, Guillemin \& Ferraz, 2000; Brislin, 1970; Çapık, Gözüm \& Aksayan, 2018). Turkish and English translations 
were carried out by a 12-person expert committee. The expert committee examined the semantic, conceptual and linguistic equivalence of all translation forms and decided on the final version of the scale before the pilot study. The final version of the scale form decided by the committee was applied to a group of 42 people for preliminary evaluation. The final form of the scale form was created through the feedback obtained from the participants. The construct validity of the scale was carried out by applying EFA and CFA. The reliability of the scale was evaluated by examining the Cronbach alpha coefficient.

\section{Results}

Consumers' Perceived Value of Sport Games Scale, which originally consisted of 16 items, was tried to be analyzed with EFA. By examining the factor loads of the items, it was determined which item loaded on which factor, and it was understood that 6 items loaded on the first factor, 4 items on the second factor, and two items on each of the other three factors. The five-dimensional structure in the original form of the scale showed consistency in Turkish culture, and it was understood that the same items loaded on the same factors. It was determined that the five subdimensions together explained approximately $75.38 \%$ of the total variance of the scale. When the factor loads of the items were examined, it was seen that they took values between .46 and .87. The naming of the dimensions was carried out as the first sub-dimension "Functional Value" consisting of 6 items, the second sub-dimension consisting of 4 items "Emotional Value" and the other subdimensions consisting of two items, respectively, "Economic Value", "Social Value" and "Epistemic Value". When the relationship coefficients of the sub-dimensions of the scale were examined, it was understood that the factors had a moderate relationship with each other. When the findings regarding the structure of the scale reached as a result of CFA were examined, it was seen that the RMSEA value of the model was .081. Other goodness of fit indices were found to be acceptable in line with the cut-off values. Reliability coefficients of the sub-dimensions of the scale range from .83 to .89 . Item total test correlations range from .54 to .87 .

\section{Discussion}

Perceived value, which is stated as one of the most important factors for marketing (Byon, Zhang \& Baker, 2013; Cronin, Brady \& Hult, 2000; Hightower, Brady \& Baker, 2002; Murray \& Howat 2002), has been tried to be examined within the scope of different parameters in the literature (Eskiler \& Altunışık , 2015; Jin, Lee, \& Lee, 2013; Kazançoğlu \& Baybars, 2016; Nuviala, GraoCruces, Pérez-Turpin, \& Nuviala, 2012; Şener \& Behdioğlu, 2013). When some researchs on perceived value are examined, it is seen that this factor is generally examined as one dimension and is mostly associated with economy (Byon, Zhang \& Baker, 2013; Cronin, Brady \& Hult, 2000; Hightower, Brady \& Baker, 2002; Howat \& Assaker, 2013; Kwon, Trail \& James, 2007). However, some researchers emphasized that the perception of value has more than one dimension and that examining it together with these dimensions may yield healthier results (Kunkel, Doyle \& Berlin, 2017; Lee, Trail, Kwon \& Anderson, 2011; Sweeney \& Soutar, 2001). Because, as a result of the detailed examination of the perceived value, it is emphasized that more consistent results can be achieved in the relationship between the marketer and the consumer (Kunkel, Doyle \& Berlin, 2017; Lee, Trail, Kwon \& Anderson, 2011). Therefore, it is thought that sports marketers and managers' multi-dimensional evaluation of the perceived value can increase the strength of the bond between them and the consumer and thus achieve the desired results in marketing strategies. In this context, it is thought that the multi-dimensional structure of the measurement tool adapted may be useful in evaluating the perceived value of consumers in sports events.

\section{Conclusion}

As a result, the findings of this study showed that Consumers' Perceived Value of Sport Games Scale adapted is consistent with the original structure in Turkish culture. It can be said that the multidimensional structure of the scale is predictive in terms of evaluating the attitude, loyalty and satisfaction of consumers towards the team they support. In addition, this scale, which includes five different consumer values, offers sports marketers and sports managers a theoretically sound and reliable structure in terms of applicability. 